\title{
Aortic Sources of Embolism
}

\author{
Elena Viedma-Guiard, Celine Guidoux, Pierre Amarenco and Elena Meseguer*
}

Department of Neurology and Stroke Center, APHP Bichat Hospital, Paris, France Université de Paris, LVTS, Inserm U1148, Paris, France

Aortic arch atheroma is a frequent finding in ischemic stroke patients. Its role as a source of cerebral emboli or a marker of atherosclerosis is unclear. Transesophageal echography is considered the gold standard for its detection, whereas computed tomography angiography is a good alternative; magnetic resonance and positron emission tomography could be proposed to better analyze plaque vulnerability. Despite the interest in this condition, the optimal antithrombotic treatment remains uncertain, while intensive lipid-lowering therapy should be recommended. This review aims to offer guidance on patients with aortic arch atheroma, about its causal role in stroke, diagnosis, and treatment based on current available evidence.

Keywords: aortic arch, embolic source, stroke, stroke therapy, stroke type diagnosis, ESUS (embolic stroke of undetermined source)

\section{AORTIC SOURCES OF EMBOLISM}

OPEN ACCESS

Edited by:

George Ntaios,

University of Thessaly, Greece

Reviewed by:

Hyo Suk Nam,

Yonsei University, South Korea Alexander Tsiskaridze,

Thilisi State University, Georgia

*Correspondence:

Elena Meseguer

elena.meseguer@aphp.fr

Specialty section:

This article was submitted to

Stroke,

a section of the journal

Frontiers in Neurology

Received: 15 September 2020

Accepted: 25 November 2020

Published: 15 January 2021

Citation:

Viedma-Guiard E, Guidoux C Amarenco $P$ and Meseguer E (2021)

Aortic Sources of Embolism.

Front. Neurol. 11:606663.

doi: 10.3389/fneur.2020.606663
Thrombi may form on ruptured atherosclerotic plaque in the aortic arch (AA) and are potentially responsible for artery-to-artery thromboembolism to the brain (1). Although this mechanism may cause ischemic stroke in some patients, AA atheroma (AAA) should generally be viewed as a marker of atherosclerotic stroke and cardiovascular disease (1). Another less frequent cause of aortic embolism is the "Cholesterol crystal embolization syndrome," a systemic disease produced by embolization of multiple primary cholesterol crystals to the distal arteries of several organs (including the kidney) and the legs, causing ischemic and inflammatory damages (2).

In this review, we will mainly describe thromboembolism from AAA, its epidemiology, its importance in the etiological assessment of the stroke, and the therapeutic options.

The presence of AAA was described in post-mortem studies $(3,4)$. In an autopsy study performed in the general population in New Orleans, the prevalence of AAA increased with age: in patients aged 25-34 years, 4.9\%; in those aged 35-44 years, 12.1\%; in those between 45 and 54 years, $22.5 \%$; and in those with $55-64$ years, up to $33 \%$ (3).

The causality between AAA and stroke was first supported by an autopsy case-control study including 500 cases (4). They analyzed the presence of ulcerated plaques of the AA; in patients with cerebrovascular disease, prevalence was $26 \%$ compared to $5 \%$ in patients with other neurologic diseases (4). In those with brain infarction without an identifiable cause, ulcerated plaque prevalence was $61 \%$ compared to $22 \%$ in those with a potential cause $(p<0.0019)$ (4). Prevalence was also higher in older patients. Ulcerated plaques were found in $21 \%$ of patients with brain infarction aged between 60 and 69 years compared with $5 \%$ in controls $(p=0.019), 31 \%$ in those aged $70-79$ years compared with $7 \%$ in controls $(p=0.01), 34 \%$ in those aged $80-89$ years compared with $17 \%$ in controls ( $p=0.128$ ), and up to $50 \%$ in patients over 90 years compared with $33 \%$ in controls $(p=0.63)(4)$. The analyses also concerned the association of ulcerated AAA and extracranial internal carotid artery stenosis, and no relationship was found (4).

These data were supported by a multicenter autopsy study, where they found that $33 \%$ of the patients presented AAA (5). In this study, stroke was significantly correlated with complicated AAA 
[odds ratio (OR) 5.8, 95\% confidence interval (CI) 1.1 to 31.7 , $p<0.05$ ], severe ipsilateral carotid artery disease (OR 3.1, 95\% CI 3.1-45.3, $p<0.001$ ), and atrial fibrillation (OR 3.5, 95\% CI 1.1-9.9, $p<0.05$ ), supporting the role of AAA in cerebral infarction (5).

The advent of transesophageal echocardiography (TEE) improved our understanding of this condition. TEE visualizes the proximal aortic segments, including part of the ascending AA, the horizontal part of the arch, and the proximal descending aorta. TEE studies described AAA in patients with transient ischemic attack (TIA) or stroke (6-8). The prevalence of AAA in stroke patients ranged $14-42 \%(1,9,10)$. In patients with TIA or minor stroke, AAA prevalence was also 40\% (8). In case-control TEE studies, patients with severe AAA (plaque $>5 \mathrm{~mm}$ ) had a higher incidence of stroke (36\% in stroke patients vs. $4 \%$ in controls) (11) and peripheral embolism (27 vs. 9\%) (12).

In 1994, a prospective case-control study including patients over 60 years found a strong and independent association between AAA and risk of ischemic stroke (13). Atheroma $\geq$ $4 \mathrm{~mm}$ was present in $14.4 \%$ of stroke patients compared to $2 \%$ of controls (patients having TEE for cardiac disorders). Statistical analyses were adjusted according to atherosclerotic risk factors; OR for ischemic stroke in case of aortic atheroma $\geq 4 \mathrm{~mm}$ was 9.1 (95\% CI 3.3-25.5; $p<0.001$ ) (13). Interestingly, $28.2 \%$ of patients with no obvious cause of stroke had plaques $\geq 4 \mathrm{~mm}$, whereas in patients with other possible or likely causes of stroke, $8.1 \%$ had this kind of plaques (13).

Similar results were reported in another prospective casecontrol study, this one with community-based controls; data were analyzed according to vascular risk factors and high-grade carotid stenosis; results showed that atheroma in the ascending aorta and AA was a risk factor for cerebral ischemia; OR for simple atheroma was 2.3 (95\% CI, 1.2-4.2) and while for complex atheroma OR was 7.1 (95\% CI 2.7-18.4) (14).

The risk of recurrent stroke in patients with known AAA has also been evaluated $(8,15-20)$. A prospective study from the French Study of the Aortic Plaques in Stroke Group found an incidence of recurrent brain infarction of $11.9 \%$ and an incidence of all vascular events of 26 per 100 person-years in patients with an $\mathrm{AAA} \geq 4 \mathrm{~mm}$ (15). According to AAA thickness, the risk of stroke recurrence increased: in patients with AAA $1-3.9 \mathrm{~mm}$, it was 3.5 per 100 person-years, whereas in patients with AAA < $1 \mathrm{~mm}$, it was 2.8 per 100 person-years $(p<0.001)(15)$. In this study, severe AAA was an independent predictor for recurrent brain infarction (relative risk, 3.8; 95\% CI 1.8-7.8; $p=0.0012$ ) (15). In a cohort study including 1231 patients with TIA or minor stroke, the incidence of recurrent vascular events at 1 year was $2.2 \%$ in patients without $\mathrm{AAA}, 4.1 \%$ in patients with moderate AAA $(<4 \mathrm{~mm})$, and $6.6 \%$ in case of severe AAA $(\geq 4 \mathrm{~mm})$ (logrank, $p$ for trend $=0.003)$ (8). Other similar studies confirmed the higher risk of stroke recurrence in case of AAA (16-20).

One meta-analysis published in 2004 by Macleod estimates the OR of stroke in patients with severe aortic atheroma of 3.76 (95\% CI 2.58-5.48), and results showed a remarkable degree of homogeneity between them (21). Another meta-analysis by Cui in 2014 had similar results; they found that AAA significantly increased the risk of stroke by almost four times $(\mathrm{OR}=3.93$, 95\% CI 2.86-5.40) (22). All these data support the role of
AAA as a potential cause of stroke. Moreover, the detection of microembolic signals using transcranial Doppler in stroke patients with AAA endorses the hypotheses of AAA as an embolic source (23-25). AAA is also considered to be a potential cause of embolism in patients with embolic stroke of undetermined source (ESUS) $(26,27)$.

However, AAA might only be a marker of generalized atheroma; its presence has been described in patients with other atherosclerotic disease such as coronary artery disease (28). Moreover, in a series of 1,200 patients with open heart surgery, $19.3 \%$ of the patients presented AAA $\geq 3 \mathrm{~mm}$ or with ulcerated or mobile components; the prevalence increased with age: from $9.6 \%$ in those aged $50-60$ years to $32.6 \%$ in those over 80 (29). Furthermore, AAA is associated with vascular risk factors such as smoking, hypercholesterolemia, hypertension, diabetes, male sex, peripheral vascular disease, and elevated plasma levels of fibrinogen and homocysteine $(1,21,30,31)$.

The presence of AAA has also been described in patients with ischemic stroke and other potential causes of stroke such as intracranial atherosclerosis, small vessel disease, or atrial fibrillation. A previous study showed that the presence of simple AAA ( $<4 \mathrm{~mm}$ or present in the descending aorta) was an independent predictor of intracranial atherosclerosis in patients with ischemic stroke (OR 1.94, 95\% CI 1.173.21) (32). Interestingly, another clinical study showed that $36.4 \%$ of patients with AAA presented small vessel disease, including cerebral microbleeds, white matter intensities, highgrade perivascular spaces, and asymptomatic lacunar infarctions (33). Moreover, in a recent article in patients with stroke and atrial fibrillation, $38.4 \%$ had complex AAA ( $>4 \mathrm{~mm}$ ); the prevalence was higher in older patients and in those with diabetes and low high-density lipoprotein cholesterol (34).

The pattern of the infarction in patients with AAA has also been analyzed, magnetic resonance (MR) studies have shown that patients with complex AAA ( $>4 \mathrm{~mm}$ or with a mobile component) had frequently small cortical lesions or subcortical single lesions (35). In another study in patients with cryptogenic stroke, the presence of multiple small lesions in multiple vascular territories were independently associated with vulnerable AAA, defined as $>6 \mathrm{~mm}$, ulcerated plaque, or soft plaque (OR 33.18, 95\% CI 4.26-258.45) (36).

The ASCOD classification analyzes the causality of AAA in stroke according to potential etiologic characteristics. In ASCOD, AAA is considered an atherothrombotic potential cause of stroke when a mobile thrombus is diagnosed and a possible cause if AAA is $\geq 4 \mathrm{~mm}$ without a mobile thrombus and is unlikely to be the cause of stroke if AAA is $<4 \mathrm{~mm}$ without a mobile thrombus (37).

In conclusion, it seems likely that AAA is a potential embolic site for the formation of the thrombus and responsible for ischemic stroke or TIA. It is also a marker of vascular risk, especially when AAA is over $4 \mathrm{~mm}$.

\section{DETECTION OF AAA}

\section{Transthoracic Echography (TTE)}

TTE can visualize the aortic root and proximal ascending aortic aorta. In selected patients, the AA and the descending aorta can 
be detected by suprasternal notch using TTE B-mode (38) and harmonic imaging (39). However, TTE is not very accurate in the detection of AAA.

\section{Transesophageal Echography (TEE)}

TEE is the more common imaging technique used in the detection of AAA. This technique has a high sensibility and specificity (40). The quality of the images allows the detection of AAA, the measure of plaque thickness, the definition of its echogenicity, and the detection of ulceration, calcification, mobile components, or thrombus (Figure 1).

TEE is performed under local anesthesia of the oropharynx. The probe is introduced in the esophagus, after cardiac visualization; the probe should be rotated $120-180^{\circ}$ counterclockwise to visualize the cross section of the entire thoracic descending aorta ( $40-45 \mathrm{~cm}$ from incisors). The arch is then imaged by slowly withdrawing the probe up to $18-20 \mathrm{~cm}$ from the incisors $(41,42)$.

TEE is usually a safe semi-invasive diagnostic technique. However, 0.1 to $13 \%$ of the patients describe minor oropharyngeal injuries, including hoarseness, sore throat, or odynophagia. Exceptionally major TEE complications including gastrointestinal bleeding or esophagus perforation may also occur (range from 0.2 to $0.5 \%$ ). TEE-associated mortality has been estimated to be $<0.01 \%$. Nearly $2 \%$ of patients under TEE have difficulties in the introduction of the probe, most of them because of a lack of patient cooperation and/or operator experience (98.5\%); exceptionally, anatomical reasons can explain these difficulties (1.5\%) (43).

\section{Computed Tomography Angiography (CTA)}

CTA is used for non-invasive evaluation of the aorta and its major branches. The high-resolution helical CTA allows detection of protruding aortic plaques and identifies locations, plaque size, and plaque density. It is especially interesting in the study of areas not visualized by TEE (e.g., the distal ascending aorta) and is the best choice for detecting vascular calcification (Figure 2). On the other hand, it is not able to assess plaque mobility $(44,45)$.

Some studies have compared TEE and CTA for AAA detection. In one of them, dual-helical CT yielded a sensitivity of $87 \%$, a specificity of $82 \%$, and an overall accuracy of $84 \%$ (46). Other studies comparing both techniques found that CTA was not as sensitive as TEE (53\%), but that it had high specificity (89\%); however, in high grade AAA, specificity increased to $99 \%$, but the sensitivity decreased to $23 \%$ (47).

Nevertheless, there are certain controversies as another study showed that CTA identifies more plaques throughout the AA and around the origins of the major cerebral arteries in particular, compared to TEE (48).

Depending on the patient's clinical conditions and available diagnostic possibilities, the physician will choose TEE or CTA for AA evaluation, taking into account that they provide sometimes complementary information.

\section{Positron Emission Tomography (PET)}

Further information can be obtained from PET, which is used to localize hypermetabolism (fluorodeoxyglucose uptake by the plaque) identifying inflammation inside the atheroma plaque.
This hypermetabolism is considered as a marker of instability, of higher risk of rupture and embolization. Novel PET tracers, which are designed to track active calcification, inflammation, hypoxia, or neoangiogenesis, may be potential markers for plaque rupture and cardiovascular risk (49).

\section{Magnetic Resonance (MR)}

MR is useful for artery wall evaluation and identification of morphologic features of atherosclerotic plaques (calcifications, fibrocellular tissue, etc.), identifying markers of instability (size of the necrotic core or intraplaque hemorrhage) $(44,45)$.

Recently 3D-multi-contrast MR imaging has been used for the detection of the AAA in three dimensions, these images are high quality and they allow a better evaluation of the plaque, providing further information about the potential risk of future complications or even the effect of treatments and prevention measures during the follow-up. This technique is able to show in detail the plaque composition and can detect vulnerable AAA described as those with intraplaque hemorrhage or superimposed thrombi and those thicker than $4 \mathrm{~mm}$ (50, 51). MR has been compared with TEE and has been shown to either overestimate or underestimate plaque size, but, as CTA, is better than TEE to evaluate some characteristics such as penetrating atherosclerotic ulcers, intramural hematoma, or pseudoaneurysm formation (52).

\section{TREATMENT}

\section{Antithrombotic Strategy}

The optimal antithrombotic treatment in patients with AAA remains uncertain. In patients with ischemic stroke and AAA, several antithrombotic strategies have been tested to prevent recurrence. They included aspirin, combination of antiplatelets, warfarin, and combination of low-intensity warfarin with aspirin. Retrospective studies showed a potential benefit of warfarin over aspirin $(17,53)$. However, these data were not confirmed in match control studies or clinical trials (54-58).

There has been only one prospective randomized trial conducted specifically in patients with AAA and stroke. The Aortic Arch Related Cerebral Hazard Trial (ARCH) compared Aspirin plus Clopidogrel $(\mathrm{A}+\mathrm{C})$ vs. warfarin with target International Normalized Ratio (INR) 2.5 (range 2-3) in patients with ischemic stroke, TIA, or peripheral embolism, and AAA $>4 \mathrm{~mm}$. Unfortunately, this trial was inconclusive because this event-driven trial did not meet its planned sample size and primary end point; it was prematurely stopped because of lack of recruitment. Another important pitfall was the lack of a third control group on aspirin only. The trial included 349 patients over more than 8 years; $7.6 \%$ of patients on $\mathrm{A}+\mathrm{C}$ and $11.3 \%$ of patients on warfarin presented cardiovascular events, vascular death, or intracranial hemorrhage (log-rank, $p=0.2)$; however, this difference was not significant [adjusted hazard ratio (HR) 0.76 ; 95\% CI $0.36-1.61 ; p=0.5$ ]. Major bleedings were similar with both treatments. Only vascular deaths were lower in the $\mathrm{A}+\mathrm{C}$ arm compared to the warfarin arm $(p=0.013)$. There was no net benefit combining primary end point events and major hemorrhages between both groups (9.9 vs. $13.6 \%$ in the $\mathrm{A}+$ $\mathrm{C}$ and warfarin arms, respectively, $\log$-rank $p=0.3$; adjusted 


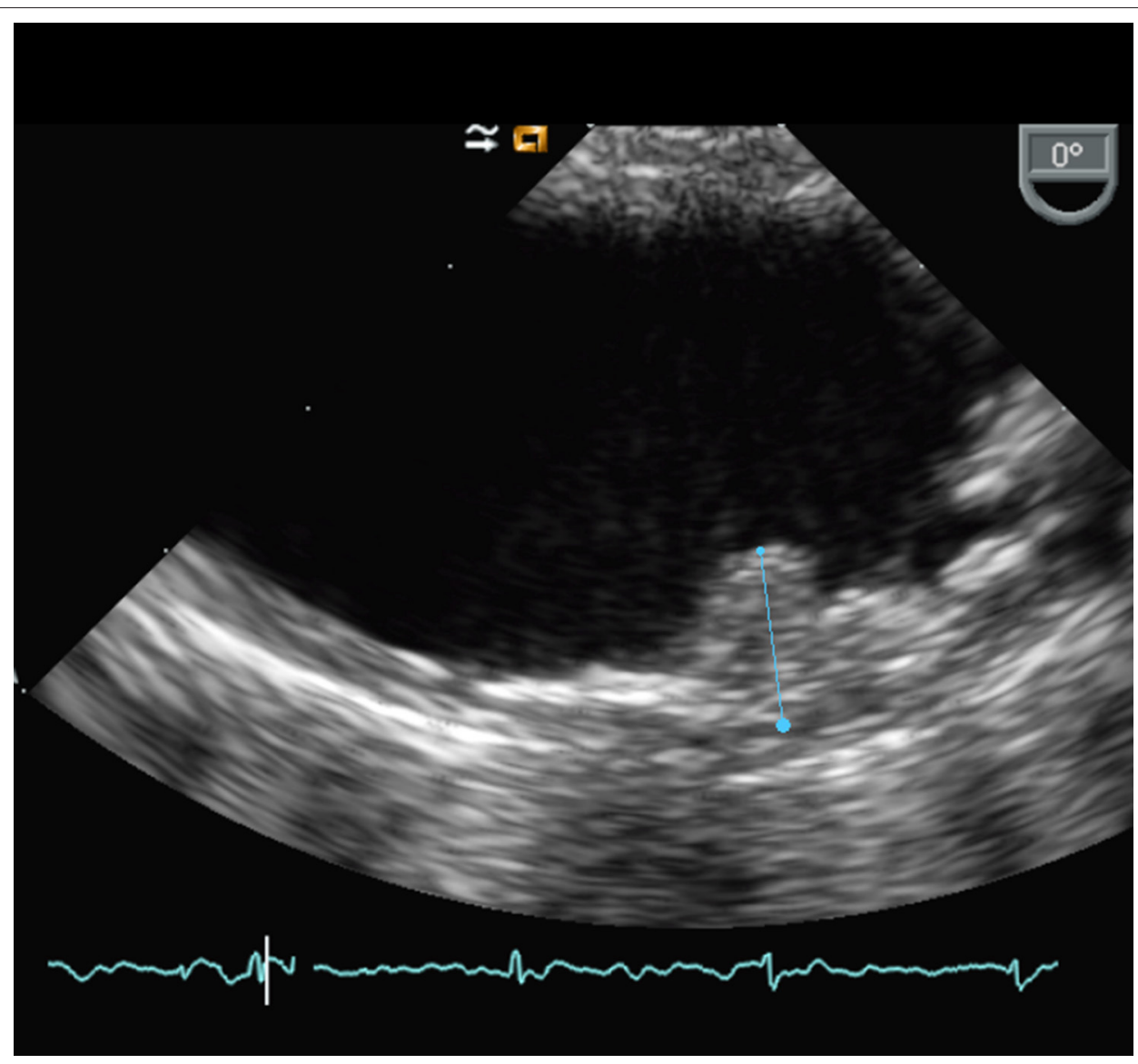

FIGURE 1 | Transesophageal echography of the aortic arch showing protruding AAA.

$p=0.5)$. However, in the group of patients with a time in therapeutic range $>77 \%$, there was a suggestion that warfarin was superior to antiplatelet strategy, without reaching statistical significance (55).

The Warfarin-Aspirin Recurrent Stroke Study (WARSS) trial compared Aspirin vs. Warfarin in patients with noncardioembolic stroke. A subgroup of patients from the WARSS with AAA showed a higher risk of stroke recurrence or death in case of atheroma and in case of bigger and complex plaques (26.7\%), compared to patients with no plaques (10\%) or small ones (16.5\%) (56). They compared aspirin $325 \mathrm{mg}$ vs. warfarin (INR 1.4-2.8), concluding that the risk was similar with both treatments (Aspirin 15.8\% vs. Warfarin 16.4, $p=$ 0.43 ), including patients with large plaques (HR 0.42, 95\% CI 0.12-1.47) (56).

Rivaroxaban Versus Aspirin in Secondary Prevention of Stroke and Prevention of Systemic Embolism in Patients with Recent Embolic Stroke of Undetermined Source (NAVIGATE ESUS) trial compared Aspirin $100 \mathrm{mg}$ vs. Rivaroxaban $15 \mathrm{mg}$ in patients with recent ESUS. A subgroup of the NAVIGATE ESUS trial included patients who had TEE; they found that $29 \%$ of them presented AAA and $8 \%$ had complex ones (57). The annual risk of stroke recurrence was $7.2 \%$ in case of complex AAA, $4.2 \%$ in non-complexes, and $5.6 \%$ in case of non-AAA (57). They compared the use of Aspirin $100 \mathrm{mg}$ vs. Rivaroxaban
$15 \mathrm{mg}$. According to the treatment in each group, no difference was found in patients with no plaques, complex plaques, and non-complex plaques (57).

A recent meta-analysis including these three previous trials found no difference for treatment with anticoagulation vs. antiplatelet in AAA (OR 0.80, 95\% CI, 0.40-1.62) (58).

In conclusion, antithrombotic treatment to prevent stroke or recurrence in patients with AAA remains uncertain, a single antiplatelet therapy strategy remains the gold standard, as generally recommended in guidelines for atherosclerotic cardiovascular disease. In case of mobile thrombus, short-term anticoagulation may be reasonable on a case-by-case basis.

\section{Hypercholesterolemia}

The use of intensive lipid-lowering therapy is recommended after transient ischemic attack and ischemic stroke of atherosclerotic origin (59). In the Treat Stroke to Target Trial (TST), patients with previous stroke or TIA and atherosclerosis disease, including AAA, were treated by statins and/or ezetimibe to achieve LDL levels of $100 \mathrm{mg} / \mathrm{dl}$ vs. LDL-level $<70 \mathrm{mg} / \mathrm{dl}$; levels lower than $70 \mathrm{mg} / \mathrm{dl}$ showed a reduction in cardiovascular events recurrence or cardiovascular death (59).

In a retrospective match-paired study during 12 years, they analyzed the effect in AAA and they found a reduction in clinical events; $12 \%$ of patients under statins compared to $29 \%$ 


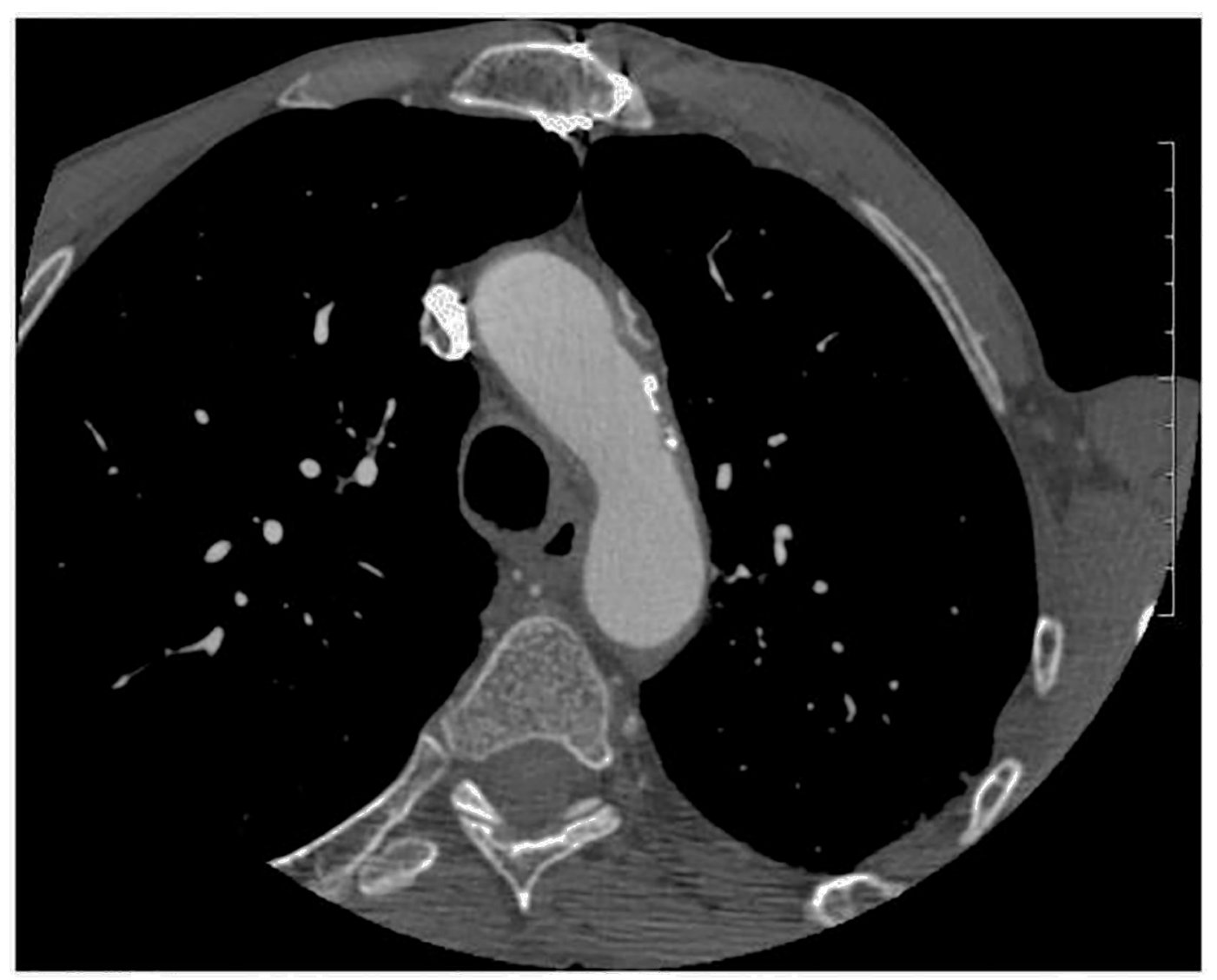

FIGURE 2 | Computed tomography angiography showing an AAA.

of non-statin patients had recurrent embolic events (OR 0.3, 95\% CI $0.2-0.6 ; p=0.0004$ ) (54). A small trial in patients with previous ischemic stroke has shown that 6 months of treatment by rosuvastatin diminishes the volume of high echoic plaques described in TEE (60). Clinical trials in patients with hypercholesterolemia and AAA have shown that long-term simvastatin (61), atorvastatin (62), and rosuvastatin (63) reduces vascular wall thickness in AAA measured using High-Resolution MRI. Simvastatin also attenuated plaque 18 F-fluorodeoxyglucose PET uptakes and decreased the maximum standardized uptake values (SUVs) in patients with AAA, suggesting the role of statins in plaque inflammation (64). Furthermore, pitavastatin stabilized plaque inflammation evaluated by PET/CT in the thoracic aorta (65).

A recent study in animal models has shown that the association of alirocumab (antiPCSK-9 antibody), evinacumab (monoclonal antibody against angiopoietin-like protein 3), and atorvastatin reduced aortic plaques in the thoracic aorta and aortic root in mice (66).

Therefore, intensive lipid-lowering therapy should be recommended in patients with AAA.

\section{Surgical}

Exceptional cases have been reported of surgical AA endarterectomy $(67,68)$. Moreover, in a study in patients under heart surgery and AAA, endarterectomy in AA was proposed; however, these patients $\mathrm{did}$ worst and presented a higher risk of stroke during the procedure (69). Therefore, there are no randomized evidence for recommending AAA endarterectomy or treatment of penetrating ulcers, and they should only be decided on a case-by-case basis.

\section{CONCLUSION}

Severe AAA is an important risk factor for stroke, especially in those patients with AAA $\geq 4 \mathrm{~mm}$, where the risk of stroke or peripheral embolism has an OR of 4 . The prevalence of severe AA is about $30 \%$ in stroke, and it is increased with age. Moreover, recurrent stroke and cardiovascular disease are more common in patients with severe AAA. However, the role of AAA is still discussed as the cause of the stroke or a marker of atherosclerosis. We suggest AAA visualization in the workup of patients with ischemic stroke as it may alter the preventive treatment. TEE is the most accurate imaging tool, and CTA could be a good alternative when TEE is not available; MR and PET could be proposed to better analyze plaque vulnerability. Patients should receive high dose of statins. An antiplatelet treatment is mandatory, and sometimes dual antiplatelet therapy or anticoagulant may be considered. 


\section{AUTHOR CONTRIBUTIONS}

EV-G and EM devised the project, the main conceptual ideas, proof outline, and wrote the manuscript. CG

\section{REFERENCES}

1. Zavala JA, Amarrenco P, Davis SM, Jones EF, Young D, Macleod MR, et al. Aortic arch atheroma. Int J Stroke. (2006) 1:74-80. doi: 10.1111/j.1747-4949.2006.00026.x

2. Saric M, Kronzon I. Cholesterol embolization syndrome. Curr Opin Cardiol. (2011) 26:472-9. doi: 10.1097/HCO.0b013e32834b7fdd

3. Strong JP, Restrepo C, Guzman M. Coronary and aortic atherosclerosis in New Orleans. II. Comparison of lesions by age, sex, and race. Lab Invest. (1978) 39:364-9.

4. Amarenco P, Duyckaerts C, Tzourio C, Hénin D, Bousser MG, Hauw JJ. The prevalence of ulcerated plaques in the aortic arch in patients with stroke. $N$ Engl J Med. (1992) 326:221-5. doi: 10.1056/NEJM199201233260402

5. Khatibzadeh M, Mitusch R, Stierle U, Gromoll B, Sheikhzadeh A. Aortic atherosclerotic plaques as a source of systemic embolism. J Am Coll Cardiol. (1996) 27:664-9. doi: 10.1016/0735-1097(95)00526-9

6. Pop G, Sutherland GR, Koudstaal PJ, Sit TW, de Jong G, Roelandt JR. Transesophageal echo- cardiography in the detection of intracardiac embolic sources in patients with transient ischemic attacks. Stroke. (1990) 21:560-5. doi: 10.1161/01.str.21.4.560

7. Tunick PA, Kronzon I. Protruding atherosclerotic plaque in the aortic arch of patients with systemic embolization: a new finding seen by transesophageal echocardiography. Am Heart J. (1990) 120:658-60. doi: 10.1016/0002-8703(90)90024-r

8. Guidoux C, Mazighi M, Lavallée P, Labreuche J, Meseguer E, Cabrejo L, et al. Aortic arch atheroma in transient ischemic attack patients. Atherosclerosis. (2013) 231:124-8. doi: 10.1016/j.atherosclerosis.2013.08.025

9. Fasseas P, Brilakis ES, Leybishkis B, Cohen M, Sokil AB, Wolf N, et al. Association of carotid artery intima-media thickness with complex aortic atherosclerosis in patients with recent stroke. Angiology. (2002) 53:185-89. doi: 10.1177/000331970205300209

10. Toyoda K, Yasaka M, Nagata S, Yamaguchi T. Aortogenic embolic stroke: a transesophageal echocardiographic approach. Stroke. (1992) 23:1056-61. doi: 10.1161/01.str.23.8.1056

11. Karalis DG, Chandrasekaran K, Victor MF, Ross JJ Jr, Mintz GS. Recognition and embolic potential of intraaortic atherosclerotic debris. J Am Coll Cardiol. (1991) 17:73-8. doi: 10.1016/0735-1097(91)90706-f

12. Tunick PA, Perez JL, Kronzon I. Protruding atheromas in the thoracic aorta and systemic embolization. Ann Intern Med. (1991) 115:423-7. doi: 10.7326/0003-4819-115-6-423

13. Amarenco P, Cohen A, Tzourio C, Bertrand B, Hommel M, Besson G, et al. Atherosclerotic disease of the aortic arch and the risk of ischemic stroke. $N$ Engl J Med. (1994) 331:1474-9. doi: 10.1056/NEJM199412013312202

14. Jones EF, Kalman JM, Calafiore P, Tonkin AM, Donnan GA. Proximal aortic atheroma. An independent risk factor for cerebral ischemia. Stroke. (1995) 26:218-24.

15. The French study of aortic plaques in Stroke Group, Amarenco P, Cohen A, Hommel M, Moulin T, Leys D, Bousser M-G. Atherosclerotic disease of the aortic arch as a risk factor for recurrent ischemic stroke. N Engl J Med. (1996) 334:1216-21. doi: 10.1056/NEJM199605093341902

16. Mitusch R, Doherty C, Wucherpfennig H, Memmesheimer C, Tepe C, Stierle U, et al. Vascular events during follow-up in patients with aortic arch atherosclerosis. Stroke. (1997) 28:36-9. doi: 10.1161/01.str.28.1.36

17. Ferrari E, Vidal R, Chevallier T, Baudouy M. Atherosclerosis of the thoracic aorta and aortic debris as a marker of poor prognosis: benefit of oral anticoagulants. J Am Coll Cardiol. (1999) 33:1317-22. doi: 10.1016/s0735-1097(99)00003-0

18. Kazui S, Levi CR, Jones EF, Quang L, Calafiore P, Donnan GA. Lacunar stroke: transoesophageal echocardiographic factors influencing long-term prognosis. Cerebrovasc Dis. (2001) 12:325-30. doi: 10.1159/000047729 provided images. PA and CG provided critical feedback and helped shape the research, analysis, and manuscript. All authors contributed to the article and approved the submitted version.

19. Dong J, Ma X, Qie J, Ji X. Aortic complex plaque predicts the risk of cryptogenic ischemic cerebrovascular disease recurrence. Aging Dis. (2016) 7:114-20. doi: 10.14336/AD.2015.0923

20. Di Tullio MR, Russo C, Jin Z, Sacco RL, Mohr JP, Homma S, et al. Aortic arch plaques and risk of recurrent stroke and death. Circulation. (2009) 119:2376-82. doi: 10.1161/CIRCULATIONAHA.108.811935

21. Macleod MR, Amarenco P, Davis SM, Donnan GA. Atheroma of the aortic arch: an important and poorly recognised factor in the aetiology of stroke. Lancet Neurol. (2004) 3:408-14. doi: 10.1016/S1474-4422(04)00806-3

22. Cui X, Li Y, Liu J, He S, Liu M. Aortic arch atheroma and the risk of stroke: a meta-analysis. J Evid Based Med. (2014) 7:185-91. doi: 10.1111/jebm.12113

23. Rundek T, Di Tullio MR, Sciacca RR, Titova IV, Mohr JP, Homma S, et al. Association between large aortic arch atheromas and high-intensity transient signals in elderly stroke patients. Stroke. (1999) 30:2683-6. doi: 10.1161/01.str.30.12.2683

24. Castellanos M, Serena J, Segura T, Pérez-Ayuso MJ, Silva Y, Dávalos A. Atherosclerotic aortic arch plaques in cryptogenic stroke: a microembolic signal monitoring study. Eur Neurol. (2001) 45:145-50. doi: $10.1159 / 000052113$

25. Viguier A, Pavy le Traon A, Massabuau P, Valton L, Larrue V. Asymptomatic cerebral embolic signals in patients with acute cerebral ischaemia and severe aortic arch atherosclerosis. J Neurol. (2001) 248:768-71. doi: $10.1007 / \mathrm{s} 004150170092$

26. Hart RG, Catanese L, Perera KS, Ntaios G, Connolly SJ. Embolic stroke of undetermined source: a systematic review and clinical update. Stroke. (2017) 48:867-72. doi: 10.1161/STROKEAHA.116.016414

27. Nouh A, Hussain M, Mehta T, Yaghi S. Embolic strokes of unknown source and cryptogenic stroke: implications in clinical practice. Front Neurol. (2016) 7:37. doi: $10.3389 /$ fneur.2016.00037

28. Fazio GP, Redberg RF, Winslow T, Schiller NB. Transesophageal echocardiographically detected atherosclerotic aortic plaque is a marker for coronary artery disease. J Am Coll Cardiol. (1993) 21:144-50. doi: 10.1016/0735-1097(93)90729-k

29. Dávila-Román VG, Barzilai B, Wareing TH, Murphy SF, Schechtman KB, Kouchoukos NT. Atherosclerosis of the ascending aorta. Prevalence and role as an independent predictor of cerebrovascular events in cardiac patients. Stroke. (1994) 25:2010-6. doi: 10.1161/01.str.25.10.2010

30. Tribouilloy C, Peltier M, Colas L, Senni M, Ganry O, Rey JL, et al. Fibrinogen is an independent marker for thoracic aortic atherosclerosis. Am J Cardiol. (1998) 81:321-6. doi: 10.1016/s0002-9149(97)00900-4

31. Tribouilly C, Peltier M, Iannetta Peltier MC, Trojette F, Andrejak M, Lesbre JP. Plasma homocysteine and severity of thoracic aortic atherosclerosis. Chest. (2000) 118:1685-9. doi: 10.1378/chest.118.6.1685

32. Nam HS, Han SW, Lee JY, Ahn SH, Ha JW, Rim SJ, et al. Association of aortic plaque with intracranial atherosclerosis in patients with stroke. Neurology. (2006) 67:1184-8. doi: 10.1212/01.wnl.0000238511.72927.3c

33. Song TJ, Kim YD, Yoo J, Kim J, Chang HJ, Hong GR, et al. Association between aortic atheroma and cerebral small vessel disease in patients with ischemic stroke. J Stroke. (2016) 18:312-20. doi: 10.5853/jos.2016. 00171

34. Suzuki M, Furuya K, Ozawa M, Miura K, Ozawa T, Matsuzono K, et al. Complex aortic arch atherosclerosis in acute ischemic stroke patients with non-valvular atrial fibrillation. J Atheroscler Thromb. (2020) 1-10. doi: $10.5551 /$ jat.58339

35. Kim SW, Kim YD, Chang HJ, Hong GR, Shim CY, Chung SJ, et al. Different infarction patterns in patients with aortic atheroma compared to those with cardioembolism or large artery atherosclerosis. J Neurol. (2018) 265:151-8. doi: 10.1007/s00415-017-8685-7

36. Kim SJ, Ryoo S, Hwang J, Noh HJ, Park JH, Choe YH, et al. Characterization of the infarct pattern caused by vulnerable aortic arch atheroma: DWI 
and multidetector row CT study. Cerebrovasc Dis. (2012) 33:549-57. doi: $10.1159 / 000338018$

37. Amarenco P, Bogousslavsky J, Caplan LR, Donnan GA, Wolf ME, Hennerici MG. The ASCOD phenotyping of ischemic stroke (Updated ASCO Phenotyping). Cerebrovasc Dis. (2013) 36:1-5. doi: 10.1159/000352050

38. Weinberger J, Azhar S, Danisi F, Hayes R, Goldman M. A new noninvasive technique for imaging atherosclerotic plaque in the aortic arch of stroke patients by transcutaneous real-time B-mode ultrasonography: an initial report. Stroke. (1998) 29:673-6. doi: 10.1161/01.str.29.3.673

39. Schwammenthal E, Schwammenthal Y, Tanne D, Tenenbaum A, Garniek A, Motro M, et al. Transcutaneous detection of aortic arch atheromas by suprasternal harmonic imaging. J Am Coll Cardiol. (2002) 39:1127-32. doi: 10.1016/s0735-1097(02)01730-8

40. Vaduganathan P, Ewton A, Nagueh SF, Weilbaecher DG, Safi HJ, Zoghbi WA. Pathologic correlates of aortic plaques, thrombi and mobile "aortic debris" imaged in vivo with transesophageal echocardiography. J Am Coll Cardiol. (1997) 30:357-63. doi: 10.1016/s0735-1097(97)00181-2

41. Amarenco P, Cohen A, Baudrimont M, Bousser MG. Transesophageal echocardiographic detection of aortic arch disease in patients with cerebral infarction. Stroke. (1992) 23:1005-9. doi: 10.1161/01.str.23.7.1005

42. Bansal RC, Shakudo M, Shah PM, Shah PM. Biplane transesophageal echocardiography: technique, image orientation, and preliminary experience in 131 patients. J Am Soc Echocardiogr. (1990) 3:348-66. doi: 10.1016/s0894-7317(14)80135-1

43. Daniel WG, Erbel R, Kasper W, Visser CA, Engberding R, Sutherland GR, et al. Safety of transesophageal echocardiography. A multicenter survey of 10,419 examinations. Circulation. (1991) 83:817-21. doi: 10.1161/01.cir.83.3.817

44. Capmany RP, Ibañez MO, Pesquer XJ. Complex atheromatosis of the aortic arch in cerebral infarction. Curr Cardiol Rev. (2010) 6:184-93. doi: $10.2174 / 157340310791658712$

45. Vizzardi E, Gelsomino S, D’Aloia A, Lorusso R. Aortic atheromas and stroke: review of literature. J Investig Med. (2013) 61:956-66. doi: 10.2310/JIM.0b013e31829cbe04

46. Tenenbaum A, Garniek A, Shemesh J, Fisman EZ, Stroh CI, Itzchak Y, et al. Dual-helical CT for detecting aortic atheromas as a source of stroke: comparison with transesophageal echocardiography. Radiology. (1998) 208:153-8. doi: 10.1148/radiology.208.1.9646807

47. Barazangi N, Wintermark M, Lease K, Rao R, Smith W, Josephson SA. Comparison of computed tomography angiography and transesophageal echocardiography for evaluating aortic arch disease. J Stroke Cerebrovasc Dis. (2011) 20:436-42. doi: 10.1016/j.jstrokecerebrovasdis.2010.02.016

48. Chatzikonstantinou A, Krissak R, Flüchter S, Artemis D, Schaefer A, Schoenberg SO, et al. CT angiography of the aorta is superior to transesophageal echocardiography for determining stroke subtypes in patients with cryptogenic ischemic stroke. Cerebrovasc Dis. (2012) 33:322-28. doi: $10.1159 / 000335828$

49. Kim J, Song HC. Role of PET/CT in the evaluation of aortic disease. Chonnam Med J. (2018) 54:143-52. doi: 10.4068/cmj.2018.54.3.143

50. Wehrum T, Dragonu I, Strecker C, Hennig J, Harloff A. Multi-contrast and three-dimensional assessment of the aortic wall using 3T MRI. Eur J Radiol. (2017) 91:148-54. doi: 10.1016/j.ejrad.2017.04.011

51. Wehrum T, Dragonu I, Strecker C, Schuchardt F, Hennemuth A, Drexl J, et al. Aortic atheroma as a source of stroke-assessment of embolization risk using 3D CMR in stroke patients and controls. J Cardiovasc Magn Reson. (2017) 19:67. doi: 10.1186/s12968-017-0379-x

52. Krinsky GA. Diagnostic imaging of aortic atherosclerosis and its complications. Neuroimaging Clin N Am. (2002) 12:437-43. doi: 10.1016/s1052-5149(02)00018-7

53. Dressler FA, Craig WR, Castello R, Labovitz AJ. Mobile aortic atheroma and systemic emboli: efficacy of anticoagulation and influence of plaque morphology on recurrent stroke. J Am Coll Cardiol. (1998) 31:134-8. doi: 10.1016/s0735-1097(97)00449-x

54. Tunick PA, Nayar AC, Goodkin GM, Mirchandani S, Francescone S, Rosenzweig BP, et al. Effect of treatment on the incidence of stroke and other emboli in 519 patients with severe thoracic aortic plaque. Am J Cardiol. (2002) 90:1320-5. doi: 10.1016/s0002-9149(02)02870-9

55. Amarenco P, Davis S, Jones EF, Cohen AA, Heiss WD, Kaste M, et al. Clopidogrel plus aspirin versus warfarin in patients with stroke and aortic arch plaques. Stroke. (2014) 45:1248-57. doi: 10.1161/STROKEAHA.113.004251
56. Mohr JP, Thompson JL, Lazar RM, Levin B, Sacco RL, Furie KL, et al. A comparison of warfarin and aspirin for the prevention of recurrent ischemic stroke. N Engl J Med. (2001) 345:1444-51. doi: 10.1056/NEJMoa011258

57. Kasner SE, Swaminathan B, Lavados P, Sharma M, Muir K, Veltkamp $\mathrm{R}$, et al. Rivaroxaban or aspirin for patent foramen ovale and embolic stroke of undetermined source: a prespecified subgroup analysis from the NAVIGATE ESUS trial. Lancet Neurol. (2018) 17:1053-60. doi: 10.1016/S1474-4422(18)30319-3

58. Ntaios G, Pearce LA, Meseguer E, Endres M, Amarenco P, Ozturk S, et al. Aortic arch atherosclerosis in patients with embolic stroke of undetermined source: an exploratory analysis of the NAVIGATE ESUS trial. Stroke. (2019) 50:3184-90. doi: 10.1161/STROKEAHA.119.025813

59. Amarenco P, Kim JS, Labreuche J, Charles H, Abtan J, Béjot Y, et al. A comparison of two LDL cholesterol targets after ischemic stroke. N Engl J Med. (2020) 382:9. doi: 10.1056/NEJMoa1910355

60. Ueno Y, Yamashiro K, Tanaka Y, Watanabe M, Miyamoto N, Shimada Y, et al. Rosuvastatin may stabilize atherosclerotic aortic plaque: transesophageal echocardiographic study in the EPISTEME trial. Atherosclerosis. (2015) 239:476-82. doi: 10.1016/j.atherosclerosis.2015.02.021

61. Corti R, Fuster V, Fayad ZA, Worthley SG, Helft G, Smith D, et al. Lipid lowering by simvastatin induces regression of human atherosclerotic lesions: two years' follow-up by high-resolution noninvasive magnetic resonance imaging. Circulation. (2002) 106:2884-7. doi: 10.1161/01.cir.0000041255.88750.f0

62. Kawahara T, Nishikawa M, Kawahara C, Inazu T, Sakai K, Suzuki G. Atorvastatin, etidronate, or both in patients at high risk for atherosclerotic aortic plaques: a randomized, controlled trial. Circulation. (2013) 127:232735. doi: 10.1161/CIRCULATIONAHA.113.001534

63. Yogo M, Sasaki M, Ayaori M, Kihara T, Sato H, Takiguchi S, et al. Intensive lipid lowering therapy with titrated rosuvastatin yields greater atherosclerotic aortic plaque regression: serial magnetic resonance imaging observations from RAPID study. Atherosclerosis. (2014) 232:31-9. doi: 10.1016/j.atherosclerosis.2013.10.007

64. Tahara N, Kai H, Ishibashi M, Nakaura H, Kaida H, Baba K, et al. Simvastatin attenuates plaque inflammation: evaluation by fluorodeoxyglucose positron emission tomography. J Am Coll Cardiol. (2006) 48:1825-31. doi: 10.1016/j.jacc.2006.03.069

65. Ono K, Kawasaki M, Tanaka R, Segawa T, Matsuo H, Watanabe S, et al. Integrated backscatter and intima-media thickness of the thoracic aorta evaluated by transesophageal echocardiography in hypercholesterolemic patients: effect of pitavastatin therapy. Ultrasound Med Biol. (2009) 35:193200. doi: 10.1016/j.ultrasmedbio.2008.08.011

66. Pouwer MG, Pieterman EJ, Worms N, Keijzer N, Jukema JW, Gromada J, et al. Alirocumab, evinacumab, and atorvastatin triple therapy regresses plaque lesions and improves lesion composition in mice. J Lipid Res. (2020) 61:365-75. doi: 10.1194/jlr.RA119000419

67. Muehrcke DD, Grimm RA, Nissen SE, Cosgrove DM 3rd. Recurrent cerebral vascular accidents are an indication for ascending aortic endarterectomy. Ann Thorac Surg. (1996) 61:1516-8. doi: 10.1016/0003-4975(95)01105-6

68. Tunick PA, Lackner H, Katz ES, Culliford AT, Giangola G, Kronzon I. Multiple emboli from a large aortic arch thrombus in a patient with thrombotic diathesis. Am Heart J. (1992) 124:239-41. doi: 10.1016/0002-8703(92) 90955-u

69. Stern A, Tunick PA, Culliford AT, Lachmann J, Baumann FG, Kanchuger MS, et al. Protruding aortic arch atheromas: risk of stroke during heart surgery with and without aortic arch endarterectomy. Am Heart J. (1999) $138(4 \mathrm{Pt}$ 1):746-52. doi: 10.1016/s0002-8703(99) 70191-2

Conflict of Interest: The authors declare that the research was conducted in the absence of any commercial or financial relationships that could be construed as a potential conflict of interest.

Copyright $\odot 2021$ Viedma-Guiard, Guidoux, Amarenco and Meseguer. This is an open-access article distributed under the terms of the Creative Commons Attribution License (CC BY). The use, distribution or reproduction in other forums is permitted, provided the original author(s) and the copyright owner(s) are credited and that the original publication in this journal is cited, in accordance with accepted academic practice. No use, distribution or reproduction is permitted which does not comply with these terms. 